\title{
PENGARUH GOOD CORPORATE GOVERNANCE DAN BUDAYA TRI HITA KARANA PADA KINERJA BANK PERKREDITAN RAKYAT
}

\author{
I Gusti Ayu Made Asri Dwija Putri' \\ I G. K. A. Ulupui \\ Ni Gusti Putu Wirawati ${ }^{3}$ \\ ${ }^{1,2,3}$ Fakultas Ekonomi dan Bisnis, Universitas Udayana, Bali, Indonesia \\ email : igamasri@yahoo.com
}

\begin{abstract}
ABSTRAK
Tujuan penelitian ini adalah mendapatkan bukti empiris implementasi Good Corporate Governance dan budaya Tri Hita Karana berpengaruh terhadap kinerja Bank Perkreditan Rakyat (BPR). Populasi penelitian adalah seluruh BPR di Bali. Penentuan sampel menggunakan metode purposive sampling. Data pada penelitian ini dikumpulkan mengunakan kuisioner yang disebarkan langsung ke objek penelitian. Jumlah BPR yang menjadi sampel pada penelitian ini adalah 65 BPR. Alat analisis pada penelitian ini adalah analisis regresi berganda. Hasil penelitian membuktikan prinsip-prinsip Good Corporate Governance dan budaya Tri Hita Karana berpengaruh pada kinerja BPR di Bali.
\end{abstract}

Kata kunci: Good corporate governance, budaya lokal, dan kinerja

\section{THE INFLUENCE OF CORPORATE GOVERNANCE AND LOCAL GENIUS TOWARDS BANK PERKREDITAN RAKYAT PERFORMANCE ABSTRACT}

The purpose of this study, namely to obtain empirical evidence that the implementation of corporate governance affect the performance of "Bank Perkreditan Rakyat" (rural banks), and the role of local culture "Tri Hita Karana "to the BPR's performance. The population is all BPR located in Badung and Denpasar. The samples using purposive sampling method. The data in this study were collected using a questionnaire are distributed directly to the object of research. "BPR" number into the sample in this study was 65 Banks. Data analyzed by model Multiple Regression Analysis. The research result show that the principles of corporate governance and the local cultural effect on the performance of BPR in Badung and Denpasar. "Bank Perkreditan Rakyat". The implication of the study is important for the government to solve the economic problem using Corporate Governance and Tri Hita Karana concept.

Keywords: Good corporate covernance, local culture, and performance

DOI: https://doi.org/10.24843/JIAB.2017.v12.i01.p03

\section{PENDAHULUAN}

Dunia perbankan mengalami kondisi terpuruk ketika krisis melanda perekonomian Indonesia pada tahun 1997-1998. Beberapa bank besar dan Bank Perkreditan Rakyat (BPR) dilikuidasi atau di bubarkan karena tidak mampu mempertahankan kinerjanya. Kondisi krisis tersebut mempengaruhi kinerja perbankan yang mengakibatkan bank mengalami ketidakseimbangan dalam fungsi intermediasi. Dalam satu sisi, perbankan sukses dalam mengumpulkan dana masyarakat namun di sisi lain penyaluran kredit kepada masyarakat mengalami penurunan. Kodisi tersebut membuat krisis kepercayaan masyarakat kepada perbankan, sehingga anggota masyarakat menarik dananya secara besar-besaran dari bank. Anggota masyarakat sebagai nasabah bank menilai bahwa menyimpan dana di bank sudah tidak aman lagi, terutama pada bank kecil seperti BPR.

BPR menurut Undang-Undang No. 7 Tahun 1992 yang telah diubah dengan Undang-Undang No. 10 Tahun 1998 merupakan bank yang melaksanakan kegiatan usaha secara konvensional yang dalam kegiatannya tidak memberikan jasa dalam lalu lintas pembayaran. Tujuan umum BPR menunjang pelaksanaan pembangunan nasional dalam rangka meningkatkan pemerataan, pertumbuhan ekonomi, dan stabilitas nasional ke arah peningkatan kesejahteraan rakyat banyak. BPR merupakan salah satu lembaga keuangan yang memberikan pelayanan dalam sektor perbankan kepada masyarakat di daerah pedesaan dan pinggiran kota, termasuk kepada pengelola Usaha Mikro Kecil dan Menegah 
(UMKM), sehingga BPR sangat diharapkan meningkatkan peran dan kontribusinya pengembangan UMKM. Untuk dapat memaksimalkan peran BPR pada UMKM dan menghadapi persaingan di antara lembaga keuangan lainnya, maka kinerja keuangan BPR perlu ditingkatkan.

Jumlah BPR di Bali berdasar badan hukum, per November 2016 sebanyak 137 BPR, yang terdiri dari 134 berbentuk Perseroan Terbatas (PT), dan 3 berbentuk Perusahaan Daerah (PD) (www.bi.go.id). Banyaknya jumlah BPR di Provinsi Bali, secara tidak langsung menimbulkan persaingan yang sangat ketat antar bank maupun persaingan dengan lembaga keuangan mikro lainnya. Jika BPR tidak mampu menjalankan fungsinya dengan baik akan menyebabkan kesehatan BPR terganggu dan berujung pada likuidasi atau pembubaran.

Pada tahun 2009 Bank Indonesia (BI) telah melikuidasi dua BPR di Bali, yaitu BPR Budi Utama di Kediri-Tabanan, dan BPR Satya Adhi Perdana (SAP) di Kuta Selatan-Kabupaten Badung. Pada bulan Mei 2010 Bank Indonesia (BI) kembali mencabut izin usaha PT. BPR Swasad Artha di Blahbatuh-Kabupaten Gianyar dan PT. BPR Argawa Utama berlokasi Mengwi-Kabupaten Badung. Penyebab BPR dilikuidasi oleh BI adalah salah kelola dan penyimpangan oleh direksi dan pengurus bank, intervensi yang tidak benar oleh pemilik bank, dan komitmen pemilik yang lemah untuk menyelamatkan BPR-nya. Salah kelola dan penyimpangan oleh direksi dan pengurus bank terutama terkait pengetahuan serta kemampuan Direksi dan Analis Officer (AO) sehingga menyebabkan terjadinya kredit macet di luar kendali. Selain itu, ada juga kredit fiktif yang melibatkan pemilik dan pengurus BPR. Akibat yang timbul dari kredit macet dan kredit fiktif adalah rasio kecukupan modal BPR melorot di bawah ketentuan BI. Dan yang lebih memilukan masih ada pemilik BPR yang mengambil dana tanpa proses yang benar sehingga mengganggu kinerja BPR. Penyebab utama timbulnya hal tersebut adalah kurangnya tata kelola perusahaan yang baik, atau BPR belum menerapkan Good Corporate Governance (GCG).

UU No. 7 tahun 1992 tentang Perbankan yang telah diubah dengan Undang-Undang No. 10 Tahun 1998 pasal 13, usaha BPR meliputi menghimpun dana dari masyarakat dalam bentuk simpanan berupa deposito berjangka, tabungan, dan/atau bentuk lainnya yang dipersamakan dengan serta memberikan kredit. BPR menempati posisi penting dalam perekonomian karena BPR berfungsi intermediasi, yaitu mempertemukan masyarakat yang kelebihan dana dan masyarakat yang membutuhkan dana. Bisnis perbankan memiliki tujuan untuk memperoleh keuntungan optimal dengan memberikan pelayanan berupa jasa keuangan kepada masyarakat. Oleh sebab itu, manajemen perbankan harus selalu mempertahankan labanya karena perolehan laba merupakan tolak ukur kinerja pengelolaan bank.

Kinerja menunjukan suatu hasil kerja dari suatu perusahaan. Hasil kerja suatu BPR dapat dinilai dari berbagai aspek. Salah satu penilaian kinerja yang komprehensif adalah penilaian kinerja berbasis Balanced Score Card (BSC). BSC menawarkan penilaian kinerja dari dua aspek, yaitu aspek keuangan dan non keuangan. Penilaian kinerja suatu Bank tidak hanya cukup dinilai dari perspektif keuangan saja, namun perlu dinilai juga dari perspektif non keuangan. Penilaian dari perspektif non keuangan, terdiri penilaian dari sisi konsumen, proses bisnis internal, proses pembelajaran dan pertumbuhan.

Penelitian terdahulu yang meneliti tentang Good Corporate Governance (GCG) dan kinerja berbasis Balanced Score Card (BSC) adalah Sukma dan Dewi (2013). Kusumawati dan Bambang (2005) meneliti tentang pengaruh Good Corporate Governance (GCG) dan kinerja. Badera (2006) meneliti tentang pengaruh Good Corporate Governance dan budaya organisasi terhadap kinerja organisasi. Hasil risetnya menemukan bahwa GCG dan budaya organisasi berpengaruh secara positif signifikan terhadap kinerja organisasi. Sudarwan (1995) meneliti pengaruh budaya nasional yang tercermin di dalam organisasi terhadap nilai-nilai akuntansi.

Peningkatan kinerja dari suatu perusahaan tidak cukup hanya menerapkan prinsip-prinsip GCG saja, namun diperlukan kemampuan manajemen bank mengadopsi dan menerapkan budaya lokal yang luhur, seperti kearifan lokal yang melekat pada individu masyarakat dan pegawai bank pada daerah tersebut. Di Bali dikenal dengan budaya Tri Hita Karana (THK). Tri Hita Karana menjelaskan tiga hal dasar yang menjadi panutan masyarakat Bali dalam membina keharmonis hubungan manusia dengan manusia, alamnya, dan Tuhan.

Penelitian ini bertujuan untuk memberikan bukti empiris pengaruh Good Corporate Governance (GCG), budaya Tri Hita Karana (THK) pada kinerja BPR di Bali yang diukur dengan Balanced Score Card (BSC). Hal ini dilakukan karena adanya persaingan bisnis yang ketat atara BPR dengan lembaga keuangan mikro lainya di Bali, seperti Lembaga Perkeditan Desa (LPD) yang berbasis lembaga adat dan koperasi. BPR sebagai salah satu 
lembaga keuangan mikro memberikan pelayanan dalam sektor perbankan kepada masyarakat di daerah pedesaan dan pinggiran kota, termasuk kepada pengelola Usaha Mikro Kecil dan Menegah (UMKM) tentunya tidak bisa lepas dari budaya masyarakat disekitarnya, yaitu budaya Tri Hita Karana (THK).

Otoritas Jasa Keuangan (OJK) sebagai lembaga pengawas perbankan telah memperketat bisnis BPR dengan menerapkan GCG dan manajemen resiko demi menghasikan kinerja yang lebih baik. Hal ini tertuang dalam Peraturan OJK (POJK) No. 4/2015 tentang Penerapan Tata Kelola yang Baik bagi BPR, POJK No 13 /2015 tentang Penerapan Manajemen Risiko Bagi BPR dan SEOJK No. 7/SEOJK.03/2016 tentang Standar Pelaksanaan Fungsi Audit Intern BPR. Minimnya penerapan GCG dan manajemen risiko membuat banyak BPR melakukan fraud (kecurangan) sehingga tidak sedikit BPR yang ditutup operasinya. Fraud yang terjadi lebih banyak akibat dari kurangnya pengendalian internal seperti kurangnya kompetensi Sumber Daya Manusia (SDM), kontrol yang tidak baik, check and balance, serta kurangnya action plan pengelola BPR. Penerapan GCG ini merupakan sebuah konsep yang menekankan pentingnya hak pemegang saham untuk memperoleh informasi dengan benar, akurat dan tepat waktu. Penerapan prinsip GCG sangat diperlukan agar perbankan dapat bertahan dan tangguh dalam menghadapi persaingan yang semakin ketat, serta dapat menerapkan etika bisnis, sehingga dapat mewujudkan iklim usaha yang sehat dan transparan.

Tahun 1999 menjadi tonggak terbentuknya Komite Nasional Kebijakan Corporate Governance (KNKCG). melalui surat keputusan menteri koordinator bidang EKUIN NO: KEP-10/M.EKUIN/ 1999 tanggal 19 Agustus 1999, yang telah menerbitkan Code of Good Corporate Governance. Dengan demikian, Salah satu cara BPR untuk tetap survive adalah dengan menerapkan prinsip-prinsip GCG. Pada tahun 2016, GCG di BPR diperbaruhi dan diatur oleh OJK dalam SE OJK No.5/SEOJK.03/2016 tentang Penerapan Tata Kelola bagi BPR, SE OJK No.6/SEOJK.03/2016 tentang Penerapan Fungsi Kepatuhan bagi BPR, SEOJK No.7/SEOJK.03/2016 tentang Standar Pelaksanaan Fungsi Audit Intern BPR. GCG sebagai proses dan struktur yang ditetapkan dalam menjalankan perusahaan, dengan tujuan utama untuk meningkatkan nilai pemegang saham dalam jangka panjang, dengan tetap memerhatikan kepentingan stakeholders (IICG, 2004). Corporate Governance/CG merupakan suatu konsep tentang tata kelola perusahaan yang sehat, konsep ini diharapkan dapat melindungi pemegang saham (stockholders) dan kreditur agar dapat memperoleh kembali investasinya, yang terdiri atas lima prinsip (yang disingkat TARIF), yaitu transparency, accountability, responsibility, independency, dan fairness (Khairandy dan Malik, 2007).

Pada dasarnya isu tentang GCG dilatarbelakangi oleh agency theory yang menyatakan permasalahan agency muncul ketika pengelolaan suatu perusahaan terpisah dari kepemilikannya. Teori keagenan dilandasi atas tiga asumsi penting (Eisenhardt, 1989), yaitu: asumsi sifat manusia (human assumptions), asumsi keorganisasian (organizational assumptions), dan asumsi informasi (information assumptions). Teori keagenan lebih menekankan pada penentuan pengaturan kontrak yang efisien dalam hubungan pemilik dengan agen. Kontrak yang efisien adalah kontrak yang menjelaskan tentang hak dan kewajiban dari kedua belah pihak sehingga dapat meminimumkan konflik keagenan. Semua pihak yang terlibat dalam hubungan keagenan ini akan selalu berusaha mendapatkan utilitas yang maksimal.

Perspektif hubungan keagenan yang terjadi di BPR adalah manajer selaku agen mempunyai kewajiban moral untuk mengelola perusahaan secara efisien untuk mengoptimalkan laba bagi para pemilik selaku prinsipal. Konflik kepentingan antara pemilik saham dan manajer dapat terjadi karena kemungkinan manajer (agent) tidak selalu berbuat sesuai dengan kepentingan pemilik (principal), sehingga memicu biaya keagenan (agency cost). Maka untuk mengatasi permasalahan agency, pihak manajer BPR perlu menerapkan Good Corporate Governance.

Penelitian terdahulu tentang GCG, yaitu penelitian Badera (2008), Rany dan Yasa (2014), Dewi dan Putri (2014) dan Kusumawati dan Bambang (2005) meneliti tentang pengaruh GCG dan kinerja, menemukan bahwa GCG berpengaruh positif pada kinerja. Mohammed dan Fatimoh (2012), Emile et al. (2014) mendapatkan hasil bahwa praktek Good Corporate Governance dipandang sangat penting bagi perusahaan karena dapat mengurangi risiko, menarik perhatian investor dan meningkatkan kinerja perusahaan.

Good Corporate Governance dapat diterima sebagai konsep yang wajib diterapkan oleh BPR karena mampu memberikan kontribusi bagi kesejahteraan masyarakat dan didukung oleh philosofi lahirnya konsep GCG. Penerapan GCG merupakan upaya untuk meningkatkan kinerja BPR. Dengan demikian, semakin baik GCG yang diterapkan oleh BPR maka kinerja BPR akan semakin baik. 
Berdasarkan penjelasan dan penelitian sebelumnya maka hipotesis sebagai berikut $\mathrm{H}_{1}$ : Good Corporate Governance berpengaruh positif pada kinerja Bank Perkreditan Rakyat.

Hofstede (1991) menjelaskan perbedaan budaya antara kelompok berbeda dengan menggunakan konsep simbol, pahlawan (heroes), ritual, dan nilai. Budaya dipandang sebagai perilaku yang dipelajari di mana menyebar pada seluruh populasi dan terjadi secara tidak sadar. Hofstede mengakui pentingnya budaya terhadap manajemen dan praktek kerja organisasi dan dengan menggunakan pendekatan mendifinisi budaya dengan merujuk kepada kerangka kerja umum makna, pemahaman sosial, nilai, kepercayaan dan symbol. Hofstede mendifinisikan budaya sebagai kumpulan pemrograman pikiran yang membedakan anggota satu kelompok dari lainnya (Verma dan Gray, 1997). Hofstede juga melihat budaya sebagai penggabungan pola pemikiran, perasaan, dan tindakan yang dipelajari oleh individual biasanya ketika anak-anak dan menjadi bagian tidak sadar dari individual dan membentuk individu bereaksi terhadap situasi tertentu.

Semua pengertian budaya di atas mengakui bahwa budaya adalah perilaku yang dipelajari dan diperoleh dari respon manusia terhadap lingkungan. Jadi ketika diperoleh maka menjadi kondisi respon manusia terhadap lingkungannya dan dengan demikian budaya mempengaruhi seluruh sistem dan proses di Negara, daerah, dan kelompok masyarakat tersebut, termasuk sistem akuntansi (Verma dan Gray, 1997).

Tri Hita Karana (THK) sebagai suatu budaya. Konsep ini dianut dan menjadi dasar kehidupan masyarakat Bali. THK menjadi suatu wujud kearifan lokal masyarakat Bali. THK mempunyai nilai-nilai luhur yang dapat menjadi pedoman masyarakat dalam menjalani kehidupan dalam segala aspek. Nilai yang terkandung dalam THK mengajarkan manusia selalu menjaga keselarasan dan keharmonisan hubungan

antara manusia dengan manusia, antara manusia dan alam/lingkungan, dan antara manusia dengan Tuhan. Penelitian terdahulu yang berkaitan dengan budaya seperti: Ahrens dan Mollana (2007), Sudarwan (1995), Badera (2006), (Riana (2010), Hofstede (1990), Indriantoro (2000), Wiyantoro (2007). Badera (2006) meneliti tentang pengaruh Good Corporate Governance dan budaya organisasi terhadap kinerja organisasi. Hasil risetnya menemukan bahwa GCG dan budaya organisasi berpengaruh secara positif signifikan terhadap kinerja organisasi. Hasil penelitian Sudarwan (1995) menemukan bahwa budaya nasional yang tercermin di dalam organisasi berpengaruh terhadap nilai-nilai akuntansi. Adiputra (2014) mendapatkan hasil bahwa terdapat pengaruh kompleksitas tugas terhadap kinerja internal auditor dan moderasi THK. Surya (2014) menemukan bahwa budaya THK dapat meningkatkan kinerja perusahaan.

BPR di Bali merupakan salah satu lembaga keuangan yang memberikan pelayanan dalam sektor perbankan kepada masyarakat di daerah pedesaan dan pinggiran kota di Bali. Tentunta BPR menyerap budaya lokal yang mengandung nilai-nilai luhur (budaya THK) dapat mendukung operasi BPR. Selain itu, budaya THK secara tidak sadar akan dibawa oleh karyawan yang bekerja di BPR ke lingkungan kerjanya. Dengan demikian dapat di hipotesiskan sebagai berikut.

$\mathrm{H}_{2}$ : Budaya Tri Hita Karana berpengaruh positif pada kinerja Bank Perkreditan Rakyat.

\section{METODE PENELITIAN}

Penelitian dilakukan pada Bank Perkreditan Rakyat (BPR) di Bali dengan mengambil sampel BPR di Kabupaten Badung dan Kota Denpasar. Di pilihnya Kabupaten Badung dan Kota Denpasar karena dua kota ini sebagai kotra metropolitan di Bali yang budayanya sudah dipengaruhi oleh budaya lain. Tabel 1 merupakan jumlah BPR yang ada di Bali berdasarkan Badan Hukumnya.

Tabel 1.

Jumlah BPR Konvensional Berdasarkan Badan Hukum di Provinsi Provinsi Bali

\begin{tabular}{clccc}
\hline No. & Kabupaten dan Kota & PT & PD & Jumlah BPR \\
\hline 1 & Badung & 52 & 0 & 52 \\
2 & Bangli & 2 & 1 & 3 \\
3 & Buleleng & 6 & 1 & 7 \\
4 & Gianyar & 27 & 1 & 28 \\
5 & Jembrana & 1 & 0 & 1 \\
6 & Karangasem & 4 & 0 & 4 \\
7 & Klungkung & 5 & 0 & 5 \\
8 & Tabanan & 24 & 0 & 24 \\
9 & Denpasar & 13 & 0 & 13 \\
& Total & 134 & 3 & 137 \\
\hline
\end{tabular}

Sumber. Bank Indonesia, 2016 
Variabel independen adalah Corporate Governance dan Budaya Tri Hita Karan (THK) sebagai budaya lokal yang sudah diserap menjadi budaya organisasi di BPR. Variabel dependennya adalah kinerja Bank Perkreditan Rakyat (BPR).

Good Corporate Governance (GCG) merupakan prinsip mengandung makna sistem tata kelola BPR yang baik dengan memperhatikan kepentingan stakeholders yang terdiri atas nasabah, pemerintah, manajemen BPR, dan masyarakat. Pengukuran Variabel GCG menggunakan kumpulan nilai atau indek yang diperoleh berdasarkan penerapan prinsip-prinsip GCG yang terdiri atas transparency, accountability, responsibility, independency, dan fairness. Data dikumpulkan dari penyebaran kuisioner yang mengandung indikator $\mathrm{CG}$, yaitu: transparency, accountability, responsibility, independency, dan fairness.

Budaya lokal yang merupakan wujud dari nilai budaya masyarakat Bali dengan mengadopsi konsep Tri Hita Karana. Indikator budaya THK, mencakup dimensi hubungan manusia dengan manusia, hubungan manusia dengan lingkungannya, dan hubungan manusia dengan Tuhan.Kinerja yang dimaksud dalam penelitian ini adalah kinerja BPR. Kinerja BPR dilihat dari pengukuran kinerja berdasar Balanced Score Card (BSC). BSC menilai kinerja BPR dari perspektif keuangan dan non keuangan. Perspektif non keuangan terdiri penilaian dari sisi konsumen, proses bisnis internal, proses pembelajaran dan pertumbuhan.

Pengumpulan data dilakukan melalui survei dengan menggunakan kuesioner. Kuisisoner penelitian mencakup pertanyaan dn pernyataan yang indikatornya mencerminkan variabel-variabel GCG, budaya Tri Hita Karana (THK), dan kinerja yang berdasarkan Balanced Score Card (BSC). Skala pengukuran variabel menggunakan skala likert 6 point. Adapun makna 6 skala linkert adalah (1) sangat tidak setuju, (2) tidak setuju, (3) agak tidak setuju, (4) agak setuju, (5) setuju, dan (6) sangat setuju.

Populasi penelitian ini adalah seluruh BPR yang berlokasi di Bali. Pada penelitian ini sampel yang di pilih adalah BPR yang ada di kabupaten Badung dan Denpasar. Pertimbangan yang dipakai memeilih BPR di Kabupaten Badung dan Kota Denpasar karena dua kota ini sebagai kotra metropolitan di Bali yang budayanya sudah dipengaruhi oleh budaya lain. Penentuan sampel menggunakan menggunakan metode purposive sampling dengan kreteria kantor pusat BPR.

Teknik analisis yang digunakan adalah analisis regresi linier berganda, yang dibantu dengan program
SPSS. Sebelum dilakukan analisis dilakukan uji validitas dan uji reliabilitas instrumen penelitian, serta uji asumsi klasik.

\section{HASIL DAN PEMBAHASAN}

Populasi penelitian berdasarkan data yang diperoleh dari website Bank Indonesia per November 2016, terlihat pada Tabel 1. Tabel 1 menunjukan BPR di wilayah Kota Denpasar berjumlah 13 buah dan di Kabupaten Badung berjumlah 52 buah. Sehingga total sampel yang digunakan dalam penelitian ini adalah 65 BPR.

Sebelum dilakukan pengumpulan data, dilakukan uji validitas dan reliabilitas terhadap kuisioner penelitian. Hasil uji menunjukan nilai cronbach alpa diatas 0,7 dan koefisien lebih besar dari 0,3 maka kuisioner dapat dikatan valid dan reliabel. Pengolahan data dilakukan dengan regresi linier berganda maka sebelum pengujian data harus lolos uji asumsi klasik. Uji asumsi klasik yang dilakukan adalah uji normalitas, uji multikolinieritas, uji autokorelasi, uji heterokedastisitas dan uji linieritas. Hasil pengujian normalitas menunjukan nilai signifikansi Kolmogorof-Smirov sebesar 0,07 berada diatas 0,05 , sehingga dikatakan data berdistribusi normal. Uji multikolinearitas dilakukan dengan melihat nilai Variance Inflantion Factor (VIF). Berdasar pengujian terlihat bahwa nilai VIF dibawah 10, sehingga dapat dikatakan tidak terjadi multikolinearitas pada model regresi ini. Demikian juga untuk uji autokorelasi, uji heterokedastisitas, dan uji linieritas terpenuhi sehingga pengujian dapat dilanjutkan.

Hasil analisis regresi linier berganda dengan program SPSS tersaji Tabel 2. Berdasarkan Tabel 2 diketahui nilai adjusted $\mathrm{R}$ square adalah 0,92 . Hal ini berarti bahwa $92 \%$ variasi kinerja BPR dapat dijelaskan oleh variasi kedua variabel independen, yaitu Good Corporate Governance (GCG) dan budaya Tri Hita Karana sedangkan sisanya 8\% disebabkan oleh faktor lain diluar model.

Hasil pengujian model regresi diperoleh nilai signifikansi sebesar 0,000. Maka sig F 0,000 < 0,05 sehingga dapat disimpulkan bahwa model dalam penelitian ini dikatakan layak atau variabel GCG dan Budaya mampu menjelaskan variabel kinerja BPR.

Hasil pengujian regresi linear berganda pada Tabel 2 menunjukkan nilai signifikansi GCG sebesar $0,000<0,05$. Hal ini menunjukkan bahwa GCG memiliki pengaruh signifikan terhadap kinerja BPR. Hasil pengujian regresi linear berganda pada Tabel 2, Budaya Tri Hita Karana menunjukkan nilai signifikansi $0,022<0,05$. Hal ini menunjukkan bahwa 
Tabel 2

Hasil Analisis Regresi Linier Berganda

\begin{tabular}{lrrrrr}
\hline \multicolumn{5}{c}{ Unstandardized Coefficients } & \multicolumn{2}{c}{ Standardized } \\
Coefficients & \\
\hline Model & B & Std. Error & Beta & t & \multicolumn{1}{c}{ Sig. } \\
(Constanta) & $-1,613$ & 0,376 & & $-4,287$ & 0,000 \\
GCG & 0,989 & 0,091 & 0,805 & 10,889 & 0,000 \\
Budaya & 0,325 & 0,139 & 0,173 & 2,342 & 0,022 \\
RSquare & & & & & 0,924 \\
Adjusted & & & & 0,921 \\
& & & & 374,811 \\
RSquare & & & & 0,000 \\
F hitung & & & &
\end{tabular}

budaya Tri Hita Karana memiliki pengaruh signifikan terhadap kinerja BPR di Bali.

Berdasarkan Tabel 1 nilai p-value sebesar 0,000 lebih kecil daripada $\alpha=0,05$, maka $\mathrm{H}_{0}$ ditolak dan $\mathrm{H}_{1}$ diterima. Hasil ini mendukung hipotesis alternatif $\left(\mathrm{H}_{\mathrm{a}}\right)$ yang menyatakan bahwa prinsip-prinsip Good Corporate Governance (GCG) berpengaruh positif pada kinerja Bank Perkreditan Rakyat (BPR) di wilayah Kota Denpasar dan Kabupaten Badung. Kinerja pada penelitian ini dilihat dari perspektif keuangan dan non keuangan. Hasil penelitian ini mendukung penelitian Kusumawati dan Bambang (2005), Badera (2006) dan Mohammed dan Fatimoh (2012).

Berdasarkan pengujian hipotesis, diperoleh hasil bahwa GCG berpengaruh positif dan signifikan terhadap kinerja berbasis balanced scorecard pada BPR di wilayah Kota Denpasar dan Kabupaten Badung. Hal ini terjadi karena GCG membantu pengelola BPR untuk mengatur bagaimana organisasi dioperasikan dan dijalankan dengan baik. GCG sebagai sarana interaksi yang mengatur antar struktur dan mekanisme yang menjamin adanya kontrol, namun tetap mendorong efisiensi dan kinerja BPR. Implementasi Good Corporate Governance dapat meningkatkan nilai BPR. Peningkatkan kinerja BPR tercermin pada peningkatan dari perspektif keuangan, perspektif pelanggan, perspektif proses bisnis internal, serta perspektif pembelajaran dan pertumbuhan.

Penerapan Good Corporate Governance (GCG) yang baik akan membuat segala kegiatan BPR berjalan secara efektif dan efisien, hal ini dikarenakan praktik GCG bertujuan untuk melindungi setiap kepentingan stakeholders. Tata kelola BPR yang baik akan menciptakan suasana yang harmonis di lingkungan BPR. Keharmonisan ini akan menjadi motivasi dan modal penting bagi BPR dalam melakukan aktifitasnya serta akan mempermudah BPR dalam mencapai tujuannya.
Hasil hipotesis kedua menyatakan bahwa budaya Tri Hita Karana (THK) berpengaruh positif dan signifikan terhadap kinerja pada Bank Perkreditan Rakyat (BPR) di wilayah Kota Denpasar dan Kabupaten Badung. Hasil ini mendukung penelitian Badera (2008) dan Riana (2010) dan Surya (2014) menyatakan bahwa budaya berpengaruh terhadap kinerja. Menerapkan budaya lokal sebagai pedoman dalam menjalankan suatu perusahan akan menimbulkan feedback yang positif dari lingkungan yang nantinya akan berpengaruh pula terhadap kinerja BPR. Peranan budaya menjadi hal penting dan dapat mendukung dalam penelolaan manajemen. Dalam penelitian ini yang dimaksudkan adalah budaya lokal dalam masyarakat Bali adalah budaya Tri Hita Karana. Tri Hita Karana dapat menjadi suatu wujud kearifan lokal masyarakat Bali. Tri Hita Karana mempunyai nilai-nilai luhur yang dapat menjadi pedoman dalam menjalani kehidupan dalam segala aspek dan wujud kearifan lokal masyarakat Bali. Nilai yang terkandung dalam Tri Hita Karana ini mengajarkan manusia selalu menjaga keselarasan dan keharmonisan hubungan antara manusia dengan manusia, hubungan antara manusia dan alam/ lingkungan, serta hubungan antara manusia dengan Tuhan. Hasil empiris menunjukan bahwa budaya THK secara langsung akan meningkatkan kinerja pada BPR khususnya yang ada di Kabupaten Badung dan Kota Denpasar.

\section{SIMPULAN}

Berdasarkan hasil analisis mengenai pengaruh implementasi Good Corporate Governance pada kinerja Bank Perkreditan Rakyat di Kabupaten Badung dan Kota Denpasar, dapat diperoleh simpulan sebagai berikut. Good Corporate Governance berpengaruh positif pada kinerja Bank Perkreditan Rakyat di Kabupaten Badung dan Kota Denpasar. 
Hal ini menunjukkan bahwa semakin baik penerapan prinsip-prinsip Good Corporate Governance maka kinerja BPR akan meningkat. Budaya Tri Hita Karana (THK) berpengaruh positif pada kinerja Bank Perkreditan Rakyat di Kabupaten Badung dan Kota Denpasar. Hal tersebut berarti bahwa semakin mendalam anggota organisasi menyerap budaya Tri Hita Karana maka semakin meningkat kinerja BPR.

Saran bagi pihak manajemen BPR agar mematuhi segala peraturan atau ketentuan mengenai perbankan khususnya BPR yang telah dibuat oleh Bank Indonesia maupun Otoritas Jasa Keuangan (OJK) sebagai pengawas perbankan. Terutama peraturan mengenai jumlah dewan direksi, dewan komisaris, dan komisaris independen agar kinerja perusahaan lebih baik sehingga terwujud Good Corporate Governance. Penelitian selanjutkan dapat menerapkan mendefinisikan budaya lain dan kontek penilaian kinerja organisasi, seperti budaya Hofstede.

\section{REFERENSI}

Ahrens, T., \& Mollona, M. (2007). Organisational Control as Cultural Practice - a Shop Floor Ethnography of a Shelffield Steel Mill, Accounting, Organization, and Scienty, 32, 305-310.

Adiputra, I Made Pradana. (2014). Budaya Tri Hita Karana Sebagai Pemoderasi Pengaruh Kompleksitas Tugas terhadap Kinerja Internal Auditor (Studi Pada Kantor Inspektorat di Provinsi Bali). Jurnal Dinamika Akuntansi, 6(2), 191-206

Badera, I., N. (2008). Pengaruh Kesesuaian Hubungan Corporate Governance dengan Hubungan Budaya Korporasi terhadap Kinerja Perusahaan, Disertasi. Universitas Gadjah Mada.

Bambang, L. S. (2005). Corporate Governance: Isu Utama Penelitian, KOMPAK, 2, 163-171.

Dewi, Kadek Krismaya, \&Putri, I G A M Asri Dwija. (2014). Pengaruh Penerapan Prinsip-Prinsip GCG pada Kinerja Keuangan Lemaba Perkreditan Desa Kabutan Gianyar, Provinsi Bali. E-jurnal akuntansi Universitas Udayana. $8(1), 70-82$.

Eisenhardt. (1989). Agency Theory: An Assesment and Review. Accounting of Management Review, 57-74.

Emile, Rimon, Aiman Ragab and Sandy Kyaw. 2014. The Effect of Corporate Govermamce on Firm Performance, Evidence from Egypt. Asian Aconomic and Financial Review. 4(12), 18651877.
Hofstede, Geert., Neuijen, Brem., Ghayv, Demise Dawal, \& Geert Sandes. (1990). Measuring Organization and Sosial Cultures: A Qualitatives Study a Cross Twenty Cases, Administrative Sciane Quartely, 35(2), 286-316

Hofstede, Geert. (1991). Culture and Organizations, Software of the Min, McGrawHill. http://www.bi.go.id/id/statistik

Indriantoro, Nur. (2000). An Empirical Study of Locus of Control and Cultural Dimensions and Moderating Variable of The Effect of Participative Budgeting on Job Performance and Satisfaction, Jurnal Ekonomi dan Bisnis Indonesia, 15(1), 97-114.

Jensen, M. C., \& Meckling, W. H., (1976). Theory of The Firm: Managerial Behavior, Agency Cost and Ownership Structure, Journal of Financial Economics, 3(4), 305-360.

Karjaya, I Wayan Hendra, \& Sisdyani, Eka Ardani. (2014). Pengaruh Tingkat pengungkpan CSR dan Mekanisme GCG pada Kinerja Keuangan Perusahaan Pertambangan. E-Jurnal Akuntansi dan Bisnis Universitas Udayana, $8(3)$.

Khairandy, R., \& Malik. (2007). Good Corporate Governance. Perkembangan Pemikiran dan Implementasinya di Indonesia dalam Perspektif Hukum, Penerbit: Kreasi Total Media. Yogyakarta

Kusumawati, Novi, Dwi, \& Bambang L. S. (2005). Analisis Pengaruh Compliance Reporting dan Struktur Dewan terhadap Kinerja, Prosiding Simposium Nasional Akuntansi 8 Solo.

Mohammed, \& Fatimoh. (2012). Impact of Corporate Governance on Banks Performance in Nigeria. Journal of Emerging Trends in Economic and Management Sciences, 3(3), 256-260.

Rany, Yoseps Yos Sudarso Anastasio, \& Yasa, Gerianta Wirawan. (2012). Pengaruh Penerapan Corporatae Governance Terhadap Return On Equity (ROE). E-Jurnal Akuntansi, 1(1), 120.

Riana, I Gede. (2010). Dampak Penerapan Budaya Tri Hita Karana terhadap Orientasi Kewirausahaan dan Orientasi Pasar serta Konsekwensinya pada Kinerja Usaha dengan Moderator Pembelajaran Bisnis. Disertasi. PDIM UB.

Setyawan, Komang Meitradi, \& Putri, I Gusti Ayu Made Asri Dwija. (2013). Pengaruh Good Corporate Governance terhadap Kinerja Keuangan Lembaga Perkreditan Desa di Kecamatan Mengwi Kabupaten Badung. 
Sudarwan. (1995). The Dynamyc Relationship Between Culture and Accounting: an Empirical Examination of The Indonesian Setting, Disertation. Case Western Reserve University. Sugiyono. (2008). Metode Penelitian Bisnis. Penerbit: Alpha Betha Bandung.

Sukma, Nyoman Pramesti dan Krisna Dewi, Komang Ayu. (2013). Penilaian Kinerja Berbasis Balanced Scorecard pada Bank Utama. E-Jurnal Akuntansi Universitas Udayana, 5(2), 497515

Surya, Ida Bagus Ketut. (2014). Pengaruh Budaya Tri Hita Karana terhadap Kinerja Perusahaan dengan Mediasi Kepemimpinan dan Komitmen Organisasional. Disertasi. Universitas Brawijaya. Verma, Sraddha, \& Gray, Sidney. (1997). The Impact of Culture on Accounting Development and Change: an Exploratory Model, A Rivised Draft of This Paper Prepared for Presentation at International Assosiation for Accounting Education and Research in Oktober, in Paris.

Wiyantoro, Lili Sugeng, \& Sabeni, Arifin. (2007). Hubungan antara Sistem Pengendalian Manajemen dengan Perilaku Dysfungsional: Budaya Nasional sebagai Variabel Moderating, Prosiding Simposium Nasional Akuntansi 10 Makasar. 